\title{
Mathematical Analysis and Numerical Solution of a Model of HIV with a Discrete Time Delay
}

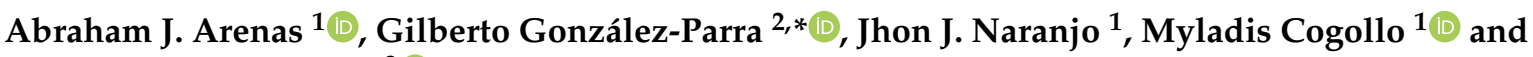 \\ Nicolás De La Espriella ${ }^{3}$
}

1 Departamento de Matemáticas y Estadística, Universidad de Córdoba, Montería 230002, Colombia; aarenas@correo.unicordoba.edu.co (A.J.A.); jjnaranjo2014@gmail.com (J.J.N.); myladiscogollo@correo.unicordoba.edu.co (M.C.)

2 Department of Mathematics, New Mexico Institute of Mining and Technology, Socorro, NM 87801, USA

3 Departamento de Física y Electrónica, Universidad de Córdoba, Montería 230002, Colombia; ndelaespriella@correo.unicordoba.edu.co

* Correspondence: gilberto.gonzalezparra@nmt.edu

check for updates

Citation: Arenas, A.J.; González-Parra, G.; Naranjo, J.J.; Cogollo, M.; De La Espriella, N. Mathematical Analysis and Numerical Solution of a Model of HIV with a Discrete Time Delay. Mathematics 2021, 9, 257. http://doi.org/10.3390/math9030257

Academic Editor: Francisco Rodríguez Received: 31 December 2020 Accepted: 25 January 2021 Published: 28 January 2021

Publisher's Note: MDPI stays neutral with regard to jurisdictional clai$\mathrm{ms}$ in published maps and institutional affiliations.

Copyright: (C) 2021 by the authors. Licensee MDPI, Basel, Switzerland. This article is an open access article distributed under the terms and conditions of the Creative Commons Attribution (CC BY) license (https:// creativecommons.org/licenses/by/ $4.0 /)$.

\begin{abstract}
We propose a mathematical model based on a set of delay differential equations that describe intracellular HIV infection. The model includes three different subpopulations of cells and the HIV virus. The mathematical model is formulated in such a way that takes into account the time between viral entry into a target cell and the production of new virions. We study the local stability of the infection-free and endemic equilibrium states. Moreover, by using a suitable Lyapunov functional and the LaSalle invariant principle, it is proved that if the basic reproduction ratio is less than unity, the infection-free equilibrium is globally asymptotically stable. In addition, we designed a non-standard difference scheme that preserves some relevant properties of the continuous mathematical model.
\end{abstract}

Keywords: HIV infection; mathematical delay model; eclipse phase; NSFD; numerical simulation

\section{Introduction}

History has recorded that infectious diseases have caused devastation in the human population. Despite the great advances in epidemic control, it was believed that infectious diseases would soon be eradicated, but this has clearly not been the case. Microorganisms adapt and evolve, and consequently, new infectious diseases such as AIDS, Ebola or COVID-19 appear, which cause many deaths. In addition, the genome of some microorganisms can sometimes change slightly and consequently, they can acquire resistance to some drugs [1]. According to the World Health Organization, since its first registration in the 1980s, Human Immunodeficiency Virus (HIV), the causative agent of Acquired Immunodeficiency Syndrome (AIDS), has caused more than 35 million deaths worldwide [2]. The greatest impact of deaths caused by AIDS occurs in underdeveloped or very poor countries, especially in sub-Saharan Africa [2,3].

HIV is an RNA virus that belongs to the retroviridae family, specifically to the lentivirus subfamily, and acts against the immune system, weakening its defense systems against infections and certain types of cancer, which is why the infected person gradually loses its immunodeficiency [4,5]. The HIV replication process is active and dynamic in the sense that when the virus enters the body, the cells that have the CD4+ receptor are infected, most of them are TCD4+ lymphocytes. After entering the cell, the HIV virus can remain latent, replicate in a controlled manner, or undergo massive replication that results in a cytopathic effect for the infected cell. In most lymphocytes the virus is latent, and the infection gradually decreases the amount of these in both the tissues and the blood. This leads the patient to a severe state of cellular immunosuppression, and then a group of microorganisms causes infections. As a consequence, there is a great mortality of people affected by HIV [6]. 
Epidemiologists conduct scientific experiments, sometimes in controlled settings through self-experimentation, to analyze the spread and possible control strategies of infectious diseases. However, designing such controlled experiments is sometimes impossible due to ethical concerns and the possible collection of erroneous data $[1,7,8]$. These reasons motivate the possibility of using mathematical models as tools to corroborate the perception of disease transmission, test theories, and suggest better intervention and control strategies.

Recently, there have been a growing literature regarding mathematical models for virus infection within-host [9-19]. These mathematical models include a variety of characteristics related to the viral dynamics. For instance, some models include discrete time delays, cell to cell viral transmissions, and the most well-known virus to cell transmission $[10,15,17,19-21]$. This article presents a new mathematical model, by means of a set of differential equations with delay, to determine the effect of how to produce viruses by target cells inside the dynamics of viruses. In this case, two types of virus-infected cells are analyzed: the cells in the eclipse phase that are not producing the virus $I_{E}$, and the cells that are actively producing the virus $I$. The cells in the eclipse phase change to the state of virus production at a $m$ rate, and the mortality rate of each cell type is $\delta_{I_{E}}$ and $\delta_{I}$, respectively. Cells in the eclipse phase may die because they could be recognized as infectious by mediators of innate immunity or due to the accumulation of DNA intermediates in the cell cytoplasm, see [22,23].

Numerous mathematical models represented by means of a system of differential equations, with or without delay, have been discretized by means of the non-standard finite difference method proposed by Ronald Mickens, see [24-34]. Their use is mainly because they are very effective in preserving certain qualitative properties of the original differential equations and the convergence, consistency and stability of their solutions have been demonstrated, see [35-46].

In this study, we also design a non-standard finite difference (NSFD) scheme that allows us to obtain numerical solutions of a set of delayed and ordinary differential equations, which describes the dynamics of HIV infection within-host. First, we apply the techniques designed by Mickens for the construction of the non-standard finite difference (NSFD) scheme to our HIV mathematical model. Secondly, we prove some main properties of the non-standard finite difference (NSFD) scheme, and that agree with qualitative properties on the HIV mathematical model with discrete time delay. One important property that the non-standard finite difference (NSFD) scheme has is that it allows us to guarantee accurate and positive solutions. This is very important when solving inverse problems related to estimation of parameters [13,47-51]. Finally, we perform some numerical simulations that show the advantages regarding accuracy and computational cost.

This paper is organized as follows. In Section 2, we present the mathematical model of HIV within-host with discrete time delay. Section 3 is devoted to the stability mathematical analysis. In Section 4, we construct the NSFD numerical scheme. We include in this section the study of some properties of this numerical scheme such as stability analysis. In Section 5, the numerical simulation results using the constructed NSFD scheme are shown, and the last section is devoted to the conclusions.

\section{Mathematical Model of HIV Within-Host with Discrete Time Delay}

We construct the mathematical model using a combination of virus facts, hypotheses, and previous proposed mathematical models within-host [9,11,14,52-55]. Despite there has been a growing number of studies related to viral dynamics within-host there are still some aspects that are not well understood [8,9,18,56-58]. Moreover, mathematical models include assumptions that make them more tractable to be able to extract useful information and test different hypotheses $[9,55,59,60]$. We start noticing that it has been argued that at least in vitro, most HIV-infected cells die before virus production begins [22,61,62]. Virusproducing cells produce virions $V$ at a rate of $N \delta_{I}$, where $N$ is the average number of infectious virions released by an infected cell during its lifetime. In general, it is accepted that most virions produced by infected cells are not infectious [63-65], and since these 
virions are not contributing to the infection of new cells, non-infectious virions are not considered in this model. On the other hand, $V$ virions that are infectious can be removed by the immune system from the population of virus-free cells at intrinsic clearance rate $C$, or they can infect target cells $(C D 4+T)$ at a $\beta$ rate, with $T$ the concentration of target cells, where $\Lambda$ is the generation rate of uninfected CD4+ T cells and $\mu_{0}$ mortality rate of uninfected cells. In the constructed mathematical model there are two classes of infected cells. The first one is the class that includes the cells in the eclipse phase which are not making the virus, $I_{E}$. The second class include the cells that are actively producing the virus, $I$. Cells in the eclipse phase transition to the class $I$ at a rate, $m$. These cells die at rate $\delta_{I_{E}}$. The cells in class $I$ then die at rate $\delta_{I}$. Cells in the eclipse phase die due to the immune systems. Notice that the number of targets cells $T$ are not virus-infected and vary depending on the parameters $\Lambda$ and the particular death rate for target cells $\mu_{0}$.

Based on the previous assumptions, we propose a model that describes the intracellular dynamics of HIV and is given by the following system of ordinary differential equations,

$$
\begin{aligned}
\frac{d I_{E}(t)}{d t} & =\beta T(t) V(t)-\left(m+\delta_{I_{E}}\right) I_{E}(t) \\
\frac{d I(t)}{d t} & =m I_{E}(t)-\delta_{I} I(t) \\
\frac{d V(t)}{d t} & =N \delta_{I} I(t)-C V(t)-\beta T(t) V(t) \\
\frac{d T(t)}{d t} & =\Lambda-\beta T(t) V(t)-\mu_{0} T(t) .
\end{aligned}
$$

Notice, that the transmission term $\beta T(t) V(t)$ also appears in the equation for virions because of the assumption that it takes only one virion to infect a target cell $[52,66]$. The possibility of multiple infected cells is excluded [66]. It also should be noted that during the eclipse phase (the time from viral entry to the active production of viral particles) the infected cells are not producing virions $[8,9,16,67,68]$. This delay affects the maximum viral load time and the probability that a viral infection will be established $[9,68-70]$, and therefore should be explicitly modeled $[9,68]$. For this case, let $\Delta>0$ be the duration of the eclipse phase and $i_{E}(t, \tau)$ the density of cells at a time $t$ that were infected $\tau$ units of time before of $t$, i.e., are infected cells of age $\tau$. Then $i_{E}(t, \Delta)$ represents the proportion of cells in the eclipse phase that go into the state of virus production, whereby

$$
\frac{d I(t)}{d t}=i_{E}(t, \Delta)-\delta_{I} I(t)
$$

Since the mortality rate of eclipse cells $\delta_{I_{E}}$ is constant, it is appropriate to assume that $i_{E}(t, \tau)$ satisfies the equation of McKendrick-Von Foerster age-structured population dynamics model, see [71] that is

$$
\frac{\partial i_{E}(t, \tau)}{\partial t}+\frac{\partial i_{E}(t, \tau)}{\partial \tau}=-\delta_{I_{E}} i_{E}(t, \tau),
$$

subject to the boundary condition $i_{E}(t, 0)=\beta T(t) V(t)$. Thus, the solution of the Equation (3) is given by $i_{E}(t, \tau)=\beta T(t-\tau) V(t-\tau) e^{-\delta_{I_{E}} \tau}$. Therefore, Equation (2) is given by

$$
\frac{d I(t)}{d t}=\beta T(t-\Delta) V(t-\Delta) e^{-\delta_{I_{E}} \Delta}-\delta_{I} I(t)
$$

The total number of cells in the eclipse phase is given by $I_{E}(t)=\int_{0}^{\Delta} i_{E}(t, \tau) d \tau$, and by integrating both sides of Equation (3) on the interval $[0, \Delta]$ we have

$$
\frac{d I_{E}(t)}{d t}=\beta T(t) V(t)-\beta T(t-\Delta) V(t-\Delta) e^{-\delta_{I_{E}} \Delta}-\delta_{I_{E}} I_{E}(t)
$$


Thus the mathematical model given in (1) takes the form

$$
\begin{aligned}
\frac{d I_{E}(t)}{d t} & =\beta T(t) V(t)-\beta T(t-\Delta) V(t-\Delta) e^{-\delta_{I_{E}} \Delta}-\delta_{I_{E} I_{E}(t)} \\
\frac{d I(t)}{d t} & =\beta T(t-\Delta) V(t-\Delta) e^{-\delta_{I_{E}} \Delta}-\delta_{I} I(t) \\
\frac{d V(t)}{d t} & =N \delta_{I} I(t)-C V(t)-\beta T(t) V(t) \\
\frac{d T(t)}{d t} & =\Lambda-\beta T(t) V(t)-\mu_{0} T(t)
\end{aligned}
$$

where $\Delta$ is the duration of the eclipse phase, $e^{-\delta_{I_{E}} \Delta}$ represents the probability that an infected cell will survive a time $\Delta$ after viral entry. Notice that $\Delta$ is a fixed time delay, and then we have a differential equation with a discrete time delay. For a better understanding of the mathematical model, we can analyze it from the following flow chart shown in Figure 1 [54]:

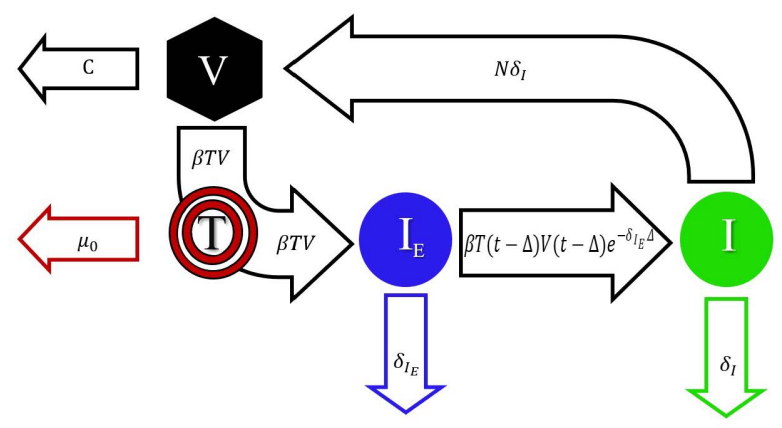

Figure 1. Flow chart of model (6).

In addition, the system (6) satisfies the initial conditions given by

$$
T(s)=\xi_{1}(s), V(s)=\xi_{2}(s), s \in[-\Delta, 0],
$$

with $\xi_{1}(s), \xi_{2}(s)$ positive continuous functions defined from the interval $[-\Delta, 0]$ to $\mathbb{R}_{+}^{2}$, and equipped with the norm $\left\|\xi_{1,2}\right\|=\sup _{-\Delta \leq s \leq 0}\left|\xi_{1,2}\right|$.

\section{Properties of the Solutions of the Mathematical Model}

Using the fundamental theory of functional differential equations [72,73], it follows that the solution of the system (6) with the initial condition (7) exists for all $t \leq 0$ and is unique.

Next, we will establish different dynamic properties of the solution of the mathematical model described by the system of Equation (6). Since the system (6) represents a biological model, it is important to determine the nature of the solution. Thus, if it is assumed that all the parameters are non-negative as well as the initial conditions $I_{E}(s), I(s), V(s), T(s)$, for $s \in[-\Delta, 0]$. Therefore, we must guarantee the positivity and boundedness of the solution $\left(I_{E}(t), I(t), V(t), T(t)\right)$ of the system $(6)$ at $[0, \infty)$. The following results characterizes these properties.

Theorem 1. If the initial conditions $I_{E}(0)=I_{E_{0}}, I(0)=I_{0}, V(0)=V_{0}, T(0)=T_{0}$ of the mathematical model (6) are positive, then the solutions $\left(I_{E}(t), I(t), V(t), T(t)\right)$ of the system (6) are positive for all $t \in[0, \infty)$. 
Proof. Let us start by noting that the solutions of the differential equations of $I_{E}(t)$ and $I(t)$ given in (6) can be written as

$$
\begin{gathered}
I_{E}(t)=e^{-\delta_{I_{E}} t}\left[I_{E_{0}}+\int_{t-\Delta}^{t} \beta T(s) V(s) e^{\delta_{I_{E}} s} d s\right], \\
I(t)=e^{-\delta_{I} t}\left[I_{0}+\int_{0}^{t} \beta T(s-\Delta) V(s-\Delta) e^{\left(\delta_{I}-\delta_{I_{E}}\right) s} d s\right] .
\end{gathered}
$$

Therefore, the positivity of the solutions $T(t)$ and $V(t)$ for all $t>0$, allows us to guarantee the positivity of $I_{E}(t)$ and $I(t)$ and thus of system (6). Thus, for $T(t)$ given as in (6) we have that $T(t)>0$, for all $t \geq 0$. Indeed, suppose that the positivity does not holds, therefore there must be a $t_{0}>0$ such that $T\left(t_{0}\right)=0, \frac{d T\left(t_{0}\right)}{d t} \leq 0$ and $T(t)>0$ for all $t \in\left[0, t_{0}\right)$, because the initial condition $T_{0}>0$. Thus, $T(t)$ must be negative from some $t_{0}$. However, in the interval $\left[0, t_{0}\right)$ the function $T(t)$ is positive, and at point $t_{0}$ the derivative at $t_{0}$ is non-positive. Thus, from the fourth equation of model (6), it follows that for $t_{0}$,

$$
\frac{d T\left(t_{0}\right)}{d t}=\Lambda-\beta T\left(t_{0}\right) V\left(t_{0}\right)-\mu_{0} T\left(t_{0}\right)=\Lambda>0,
$$

which contradicts that $\frac{d T\left(t_{0}\right)}{d t} \leq 0$. Therefore, we must have $T(t)>0$, for all $t \geq 0$. Now, we affirm that if $V(t)$ is given by the system (6), it follows that

$$
V(t)>0, \text { for all } t \geq 0 .
$$

Indeed, suppose that there exists a $t_{1}>0$ such that $V\left(t_{1}\right)=0, \frac{d V\left(t_{1}\right)}{d t} \leq 0$ and $V(t)>0$ for all $t \in\left[0, t_{1}\right)$. Then it holds that $I(t)>0$ for all $t \in\left[0, t_{1}\right)$. Otherwise, there should be a $t_{2}$ such that $0<t_{2}<t_{1}, I\left(t_{2}\right)=0, \frac{d I\left(t_{2}\right)}{d t} \leq 0$ and $I(t)>0$ for all $t \in\left[0, t_{2}\right)$. Thus, from the second equation of system (6), if follows that for $t_{2} \in\left(\Delta, t_{1}\right)$ it holds

$$
\frac{d I\left(t_{2}\right)}{d t}=\beta T\left(t_{2}-\Delta\right) V\left(t_{2}-\Delta\right) e^{-\delta_{I_{E}} \Delta}-\delta_{I} I\left(t_{2}\right)=\beta T\left(t_{2}-\Delta\right) V\left(t_{2}-\Delta\right) e^{-\delta_{I_{E}} \Delta} .
$$

But, $-\Delta<t_{2}-\Delta<t_{1}-\Delta<t_{1}$. From the initial conditions given by (7) and the hypothesis for $V(0)>0$ it follows that $V\left(t_{2}-\Delta\right)>0$. This, contradicts that $\frac{d I\left(t_{2}\right)}{d t} \leq 0$. Thus, $I(t)>0$, for all $t \in\left[0, t_{1}\right)$. Next, from third equation of system (6) for $t_{1}>0$,

$$
\frac{d V\left(t_{1}\right)}{d t}=N \delta_{I} I\left(t_{1}\right)-C V\left(t_{1}\right)-\beta T\left(t_{1}\right) V\left(t_{1}\right)=N \delta_{I} I\left(t_{1}\right)>0 .
$$

This is a contradiction since $\frac{d V\left(t_{1}\right)}{d t} \leq 0$. Therefore, $V(t)>0$ for all $t \geq 0$.

Theorem 2. The solution $\left(I_{E}(t), I(t), V(t), T(t)\right)$ of system (6) is uniformly bounded in $[0, \infty)$.

Proof. From system (6), one can see that

$$
\frac{d I_{E}(t)}{d t}+\frac{d I(t)}{d t}+\frac{d T(t)}{d t}=\Lambda-\delta_{I_{E}} I_{E}(t)-\delta_{I} I(t)-\mu_{0} T(t) \leq \Lambda-M\left(I_{E}(t)+I(t)+T(t)\right),
$$

where $M=\min \left\{\delta_{I_{E}}, \delta_{I}, \mu_{0}\right\}$. This implies that

$$
I_{E}(t)+I(t)+T(t) \leq e^{-M t}\left[I_{E_{0}}+I_{0}+T_{0}+\int_{0}^{t} \Lambda e^{M s} d s\right]=e^{-M t}\left[I_{E_{0}}+I_{0}+T_{0}\right]+\frac{\Lambda}{M}\left(1-e^{-M t}\right) .
$$


Thus,

$$
\limsup _{t \rightarrow \infty}\left(I_{E}(t)+I(t)+T(t)\right) \leq \frac{\Lambda}{M}
$$

Accordingly, $I_{E}(t), I(t)$ and $T(t)$ are uniformly boundedness. Even more, given $\varepsilon>0$, there exists $t_{1}>0$ such that for all $t \geq t_{1}$,

$$
I(t) \leq \frac{\Lambda}{M}+\varepsilon
$$

Then, since $\frac{d V(t)}{d t} \leq N \delta_{I} I(t)-C V(t)$, and $V(t)>0$ for all $t>t_{1}$, one obtains that

$$
\frac{d V(t)}{d t}+C V(t) \leq N \delta_{I}\left(\frac{\Lambda}{M}+\varepsilon\right)
$$

It follows that

$$
V(t) \leq V_{0} e^{-C t}+\left(1-e^{-C t}\right)\left(\frac{N \delta_{I}}{C}\right)\left(\frac{\Lambda}{M}+\varepsilon\right)
$$

As $t \longrightarrow \infty$, then $V(t) \leq\left(\frac{N \delta_{I}}{C}\right)\left(\frac{\Lambda}{M}+\varepsilon\right)$. Since $\epsilon>0, V(t)$ is uniformly boundedness. This completes the proof.

\subsection{Equilibrium Points}

The model described by the system of differential Equation (6) has two stationary states, the first one corresponds to the disease-free equilibrium and the second to the endemic equilibrium, which we will denote $P^{0}$ and $P^{*}$ respectively. To determine both states we must calculate the critical points of the system (6) by setting $\frac{d I_{E}(t)}{d t}=\frac{d I(t)}{d t}=$ $\frac{d V(t)}{d t}=\frac{d T(t)}{d t}=0$. Thus, we have

$$
\begin{aligned}
& 0=\beta T V-\beta T V e^{-\delta_{I_{E}} \Delta}-\delta_{I_{E}} I_{E} \\
& 0=\beta T V e^{-\delta_{I_{E}} \Delta}-\delta_{I} I \\
& 0=N \delta_{I} I-C V-\beta T V \\
& 0=\Lambda-\beta T V-\mu_{0} T .
\end{aligned}
$$

The disease-free equilibrium point of a model are solutions of steady state in the absence of infection. For this case, we must consider $I_{E}=0, I=0, V=0$, and $T>0$, in the system (11). Then $P^{0}$ will be of the form $P^{0}=\left(0,0,0, T^{0}\right)$, where $T^{0}=\frac{\Lambda}{\mu_{0}}$. Therefore, $P^{0}=\left(0,0,0, \frac{\Lambda}{\mu_{0}}\right)$.

On the other hand, we can determine the basic reproductive number using the next generation matrix methodology. With the terms of infection and viral production in the mathematical model (11), matrices $\mathrm{F}$ and $\mathrm{V}$ are given by

$$
\mathbb{F}=\left(\begin{array}{ccc}
0 & 0 & \beta T^{0}\left(1-e^{-\delta_{I_{E}} \Delta}\right) \\
0 & 0 & \beta T^{0} e^{-\delta_{I_{E}} \Delta} \\
0 & 0 & 0
\end{array}\right), \mathbb{V}=\left(\begin{array}{ccc}
\delta_{I_{E}} & 0 & 0 \\
0 & \delta_{I} & 0 \\
0 & N \delta_{I} & C+\beta T^{0}
\end{array}\right),
$$


where $T^{0}=\frac{\Lambda}{\mu_{0}}$, which it is the number of target cells before infection. Thus, the basic reproductive number $\mathcal{R}_{0}$, is calculated as the spectral radius of the matrix given by

$$
\begin{aligned}
\mathbb{F} \mathbb{V}^{-1} & =\left(\begin{array}{ccc}
0 & 0 & \beta T^{0}\left(1-e^{-\delta_{I_{E}} \Delta}\right) \\
0 & 0 & \beta T^{0} e^{-\delta_{I_{E}} \Delta} \\
0 & 0 & 0
\end{array}\right)\left(\begin{array}{ccc}
\frac{1}{\delta_{I_{E}}} & 0 & 0 \\
0 & -\delta_{I} & 0 \\
0 & -\frac{N}{C+\beta T^{0}} & \frac{1}{C+\beta T^{0}}
\end{array}\right) \\
& =\left(\begin{array}{ccc}
0 & -\frac{N \beta T^{0}\left(1-e^{-\delta_{I_{E}} \Delta}\right)}{\beta T^{0}+C} & \frac{\beta T^{0}\left(1-e^{-\delta_{I} \Delta}\right)}{\beta T^{0}+C} \\
0 & -\frac{N \beta T^{0} e^{-\delta_{I_{E}} \Delta}}{\beta T^{0}+C} & \frac{\beta T^{0} e^{-\delta_{I} \Delta}}{\beta T^{0}+C} \\
0 & 0 & 0
\end{array}\right) .
\end{aligned}
$$

Therefore, the basic reproductive number $\mathcal{R}_{0}$ is given by

$$
\mathcal{R}_{0}=\frac{N \beta \Lambda e^{-\delta_{I_{E}} \Delta}}{C \mu_{0}+\beta \Lambda} .
$$

Now, the endemic equilibrium point of a model is its steady-state solutions in the presence of infection or disease, for which it must be considered $I_{E}>0, I>0, V>0$ and $T>0$ in the system (11.) Then $P^{*}$ will be of the form $P^{*}=\left(I_{E}^{*}, I^{*}, V^{*}, T^{*}\right)$. In this case, from the system (11) the following equalities are obtained

$$
\begin{gathered}
I_{E}^{*}=\frac{\beta T^{*} V^{*}\left(1-e^{-\delta_{I_{E}} \Delta}\right)}{\delta_{I_{E}}} . \\
I^{*}=\frac{\beta T^{*} V^{*} e^{-\delta_{I_{E}} \Delta}}{\delta_{I}} . \\
I^{*}=\frac{V^{*}}{N \delta_{I}}\left(C+\beta T^{*}\right) . \\
T^{*}=\frac{\Lambda}{\beta V^{*}+\mu_{0}} .
\end{gathered}
$$

Replacing (16) in (14) and (15), is obtains

$$
I^{*}=\frac{\beta \Lambda V^{*} e^{-\delta_{I_{E}} \Delta}}{\delta_{I}\left(\beta V^{*}+\mu_{0}\right)}=\frac{V^{*}}{N \delta_{I}}\left(C+\frac{\beta \Lambda}{\beta V^{*}+\mu_{0}}\right) .
$$

Then

$$
V^{*}=\frac{N \beta \Lambda e^{-\delta_{I_{E}} \Delta}-C \mu_{0}-\beta \Lambda}{C \beta}=\frac{\left(C \mu_{0}+\beta \Lambda\right) \frac{N \beta \Lambda e^{-\delta_{I_{E}} \Delta}}{C \mu_{0}+\beta \Lambda}-1}{C \beta} .
$$

Thus, if $\mathcal{R}_{0}>1$, then $N \beta \Lambda e^{-\delta_{I_{E}} \Delta}-C \mu_{0}-\beta \Lambda>0$. Hence, we can write $V^{*}$ as

$$
V^{*}=\frac{\left(C \mu_{0}+\beta \Lambda\right)\left(\mathcal{R}_{0}-1\right)}{C \beta} .
$$

Next, we replace (18) in (17) to get

$$
I^{*}=\frac{N \beta \Lambda e^{-\delta_{I_{E}} \Delta}-C \mu_{0}-\beta \Lambda}{\delta_{I} \beta e^{\delta_{I_{E}} \Delta}\left(N e^{-\delta_{I_{E}} \Delta}-1\right)}=\frac{\left(C \mu_{0}+\beta \Lambda\right)\left(\mathcal{R}_{0}-1\right)}{\delta_{I} \beta e^{\delta_{I_{E}} \Delta}\left(N e^{-\delta_{I_{E}} \Delta}-1\right)} .
$$


Now, substituting (18) in (16) one gets

$$
T^{*}=\frac{\Lambda C}{\left(C \mu_{0}+\beta \Lambda\right)\left(\mathcal{R}_{0}-1\right)+C \mu_{0}} .
$$

Finally, we replace (18) and (21) in (13) to obtain

$$
I_{E}^{*}=\frac{\left(N \beta \Lambda e^{-\delta_{I_{E}} \Delta}-C \mu_{0}-\beta \Lambda\right)\left(e^{\delta_{I_{E}} \Delta}-1\right)}{\delta_{I} \beta e^{\delta_{I_{E}} \Delta}\left(N e^{-\delta_{I_{E}} \Delta}-1\right)}=\frac{\left(C \mu_{0}+\beta \Lambda\right)\left(\mathcal{R}_{0}-1\right)\left(e^{\delta_{I_{E}} \Delta}-1\right)}{\delta_{I} \beta e^{\delta_{I_{E}} \Delta}\left(N e^{-\delta_{I_{E}} \Delta}-1\right)}
$$

Note that $I_{E}^{*}>0, I^{*}>0, V^{*}>0$ and $T^{*}>0$ if only if $\mathcal{R}_{0}=\frac{N \beta \Lambda e^{-\delta_{I E} \Delta}}{C \mu_{0}+\beta \Lambda}>1$. Thus, $N e^{-\delta_{I_{E}} \Delta}>\frac{C \mu_{0}+\beta \Lambda}{\beta \Lambda}>1$.

\subsection{Local Stability of the Equilibrium Points}

Theorem 3. The disease-free equilibrium point $P^{0}$ of the system (6) is locally asymptotically stable if $\mathcal{R}_{0}<1$.

Proof. The eigenvalues of the Jacobian matrix of system (6) evaluated at point $P^{0}$, are given as the roots of polynomial

$$
\left(-\delta_{I}-\lambda\right)\left(-\mu_{0}-\lambda\right)\left[\lambda^{2}+\left(\delta_{I}+C+\frac{\beta \Lambda}{\mu_{0}}\right) \lambda+\left(\delta_{I} C+\frac{\delta_{I} \beta \Lambda}{\mu_{0}}-\frac{\beta e^{-\delta_{I_{E}} \Delta} N \delta_{I} \Lambda}{\mu_{0}}\right)\right]=0 .
$$

Therefore, the first two eigenvalues of the Jacobian matrix evaluated at $P^{0}$ are $\lambda_{1}=$ $-\delta_{I}<0$ and $\lambda_{2}=-\mu_{0}<0$.

Next, since $\mathcal{R}_{0}<1$ then the coefficients of equation

$$
\lambda^{2}+\left(\delta_{I}+C+\frac{\beta \Lambda}{\mu_{0}}\right) \lambda+\frac{\delta_{I}}{\mu_{0}}\left(C \mu_{0}+\beta \Lambda\right)\left(1-\mathcal{R}_{0}\right)=0,
$$

are positives. Thus, since there is no sign change between its terms, and by Descartes' sign rule it is concluded that Equation (23) does not have positive roots. Now, if $\lambda$ is replaced by $-\lambda$ in (23) then

$$
\lambda^{2}-\left(\delta_{I}+C+\frac{\beta \Lambda}{\mu_{0}}\right) \lambda+\frac{\delta_{I}}{\mu_{0}}\left(C \mu_{0}+\beta \Lambda\right)\left(1-\mathcal{R}_{0}\right)=0 .
$$

Thus, if $\mathcal{R}_{0}<1$ Equation (24) has two sign changes in its terms, and by Descartes' sign rule it is concluded that there are exactly two negative roots in Equation (23). Therefore, $P^{0}=\left(0,0,0, \frac{\Lambda}{\mu_{0}}\right)$ is locally asymptotically stable if $\mathcal{R}_{0}<1$.

Theorem 4. The $P^{*}$ endemic point of the system (6) is locally asymptotically stable if $\mathcal{R}_{0}>1$. 
Proof. We note that $R_{1}=N e^{-\delta_{I_{E}} \Delta}-1>0$. Thus, the characteristic equation is given by

$$
\left(-\delta_{I_{E}}-\lambda\right)\left|\begin{array}{ccc}
-\delta_{I}-\lambda & \frac{C e^{-\delta_{I_{E}} \Delta}}{R_{1}} & \frac{\beta \Lambda R_{1} e^{-\delta_{I_{E}} \Delta}}{C}-\mu_{0} e^{-\delta_{I_{E}} \Delta} \\
N \delta_{I} & -C-\frac{C}{R_{1}}-\lambda & \mu_{0}-\frac{\beta \Lambda R_{1}}{C} \\
0 & -\frac{C}{R_{1}} & -\frac{\beta \Lambda R_{1}}{C}-\lambda
\end{array}\right|=0
$$

Therefore, the first eigenvalue of the Jacobian matrix will be $\lambda_{1}=-\delta_{I_{E}}<0$, and the other, are the roots of polynomial

$$
\lambda^{3}+\left(\delta_{I}+C+\frac{C}{R_{1}}+\frac{\beta \Lambda R_{1}}{C}\right) \lambda^{2}+\left(\frac{\delta_{I} \beta \Lambda R_{1}}{C}+\beta \Lambda R_{1}+\frac{C \mu_{0}}{R_{1}}\right) \lambda+\delta_{I}\left(C \mu_{0}+\beta \Lambda\right)\left(\mathcal{R}_{0}-1\right)=0
$$

If $\mathcal{R}_{0}>1$ all the coefficients of Equation (25) are positive, i.e., there is no sign change between their terms, and by Descartes's sign rule it is concluded that there are no positive roots. Now if $\lambda$ is replaced by $-\lambda$ in (25) it gives us that

$$
-\lambda^{3}+\left(\delta_{I}+C+\frac{C}{R_{1}}+\frac{\beta \Lambda R_{1}}{C}\right) \lambda^{2}-\left(\frac{\delta_{I} \beta \Lambda R_{1}}{C}+\beta \Lambda R_{1}+\frac{C \mu_{0}}{R_{1}}\right) \lambda+\delta_{I}\left(C \mu_{0}+\beta \Lambda\right)\left(\mathcal{R}_{0}-1\right)=0
$$

Then, if $\mathcal{R}_{0}>1$ the polynomial (26) has three sign changes between its terms, and by Descartes's sign rule it is concluded that there are exactly three negative roots of Equation (25). Thus, $P^{*}$ is locally asymptotically stable if $\mathcal{R}_{0}>1$.

\subsection{Global Stability Analysis of the Mathematical Model}

Since the variable $I_{E}$ does not appear in the other three equations, without loss of generality we will only consider the following three-dimensional system,

$$
\begin{aligned}
& \frac{d I(t)}{d t}=\beta T(t-\Delta) V(t-\Delta) e^{-\delta_{I_{E}} \Delta}-\delta_{I} I(t) \\
& \frac{d V(t)}{d t}=N \delta_{I} I(t)-(C+\beta T(t)) V(t) \\
& \frac{d T(t)}{d t}=\Lambda-\beta T(t) V(t)-\mu_{0} T(t)
\end{aligned}
$$

To analyze the global stability of the equilibrium points of the system (27), we use the method of the Lyapunov's functions, and we will use the Volterra function

$$
G(x)=x-1-\ln x
$$

for $x>0$, which is no negative for any $x>0$ and $G(x)=0$ if and only if $x=1$.

Theorem 5. If $\mathcal{R}_{0}<1$ then the disease-free equilibrium point $P_{f}=\left(0,0, \frac{\Lambda}{\mu_{0}}\right)$ of system (27) is globally asymptotically stable.

Proof. We define the Lyapunov functional

$$
\mathcal{V}(t)=e^{-\delta_{I_{E}} \Delta} T^{0} G\left(\frac{T(t)}{T^{0}}\right)+\frac{1}{N} V(t)+I(t)+e^{-\delta_{I_{E}} \Delta} \int_{0}^{\Delta} \beta T(t-\theta) V(t-\theta) d \theta .
$$

Now, calculating the time derivative of $\mathcal{V}(t)$ along the solution of model (27), one gets that 


$$
\begin{aligned}
& \frac{d \mathcal{V}(t)}{d t}=e^{-\delta_{I_{E}} \Delta} \frac{T(t)-T^{0}}{T(t)} \frac{d T(t)}{d t}+\frac{1}{N} \frac{d V(t)}{d t}+\frac{d I(t)}{d t}+e^{-\delta_{I_{E}} \Delta} \frac{d}{d t} \int_{0}^{\Delta} \beta T(t-\theta) V(t-\theta) d \theta \\
& =-\mu_{0} e^{-\delta_{I_{E}} \Delta} \frac{\left(T(t)-T^{0}\right)^{2}}{T(t)}-e^{-\delta_{I_{E}} \Delta} \beta T(t) V(t)+e^{-\delta_{I_{E}} \Delta} \beta V(t) T^{0}+\delta_{I} I(t)-\frac{C}{N} V(t)-\frac{\beta T(t) V(t)}{N} \\
& +\beta T(t-\Delta) V(t-\Delta) e^{-\delta_{I_{E}} \Delta}-\delta_{I} I(t)-\beta T(t-\Delta) V(t-\Delta) e^{-\delta_{I_{E}} \Delta}-\delta_{I} I(t)+e^{-\delta_{I_{E}} \Delta} \beta T(t) V(t) \\
& \leq-\mu_{0} e^{-\delta_{I_{E}} \Delta} \frac{\left(T(t)-T^{0}\right)^{2}}{T(t)}+\frac{C}{N}\left(\mathcal{R}_{0}-1\right) \text {. }
\end{aligned}
$$

\section{Design of a NSFD Scheme for the Mathematical Model}

The use of differential equations in the modeling of the transmission of infectious diseases has represented a versatile tool to understand better the dynamics of a variety of infectious diseases $[7,59,60,74-76]$. Mathematical models based on differential equations have been useful to study how to reduce the burden of infectious diseases. The models allow the determination of optimal controls and estimate the impact of a variety of virus on the disease dynamics $[67,75,77]$. One advantage of mathematical models is that different simulations can be performed, and this allows us to analyze different main driven factors of epidemics under a variety of complex scenarios $[8,11,59]$. However, there are no general formulas that allow the obtaining of precise analytical solutions for many differential equation systems. These solutions exist only occasionally and are often difficult to find, so good approximations are necessary that preserve the qualitative properties of said solution, for which numerical methods have been used, see [24,25,31,48-50,78-83].

Discrete epidemic models generated by numerical methods contain additional parameters to those that already exist in differential equations, such as the time and space steps. Variations in these additional parameters can generate solutions to the discrete equations that do not correspond to any solution of the original differential equations, producing fictitious bifurcations, artificial chaos, spurious solutions, and false stable states [24-26,45,83,84]. Therefore, we must choose numerical discrete schemes that guarantee the qualitative properties of the mathematical models. There are several methods that can be used to obtain accurate solutions. For instance, the Richardson extrapolation on uniform and nonuniform grids or NSFD schemes have been used for that end [45,85-90] .

Another, important aspect where a robust numerical method plays an important role is when solving inverse problems to estimate the parameters of the model $[48,51,56,57,91,92]$. Thus, for mathematical models of a variety of virus is of paramount importance to have a robust and efficient numerical method for solving the differential equations [25,49,51]. Usually, when a differential equation is solved numerically a certain tolerance is prescribed and this has an impact in the success in estimating the parameters $[48,49,93,94]$. In this paper, we deal with a mathematical model that is based on system of differential equations with discrete time delay $[17,32,60,72,95-97]$. There are different numerical methods to deal with this type of equations, and some are analogous to the ones used for ordinary differential equations but with additional issues [50,98-102]. One particular numerical method that we are interested in is by using NSFD schemes to guarantee some properties of the continuous mathematical model. Some previous works using this methodology have been developed for linear and nonlinear delay differential equations [103-107].

For the construction of a discrete numerical scheme that allows us to efficiently approximate the solutions of the system (6), we use the methodology proposed by Ronald 
Mickens, see [24-27]. In that order of ideas, for the discrete approximation of the time derivative of a function $X(t) \in C^{1}(\mathbb{R})$, we define the non-standard derivative as

$$
\frac{d_{N} X(t)}{d t}=\frac{X(t+h)-X(t)}{\varphi(h)}+\mathcal{O}(h),
$$

where $\varphi(h)$ is a real positive valued function that satisfies $\varphi(h)=h+\mathcal{O}\left(h^{2}\right)$, and $N$ is to denote the non-standard derivative.

Although there is no general algorithm for constructing an NSFD schema that approximates the solutions of a given system of differential equations, the following general rules are often useful to correctly design these schemes.

Rule 1. The discrete derivatives in a numerical scheme must be of the same orders as the continuous derivatives that appear in the differential equation.

Rule 2. Discrete derivatives may have non-trivial denominators.

Rule 3. Nonlinear terms that appear in differential equations must have non-local representations.

Rule 4. The numerical solution must preserve all the special conditions that hold for the solutions of the corresponding differential equations.

Rule 5. The scheme must not introduce unnecessary or false solutions, i.e., convergence to false steady states.

Let us denote by $I_{E}^{n}, I^{n}, V^{n}$ and $T^{n}$ the approximations of $I_{E}(n h), I(n h), V(n h)$ and $T(n h)$, respectively, for $n=0,1,2 \ldots$, and for $h$ size step in time of the scheme. The value of $I_{E}^{n+1}$ for $n=0,1, \cdots$, is calculated using Equation (8) and a quadrature formula. For this case, we use

$I_{E}^{n+1}=e^{-\delta_{I_{E}} \Delta(n+1) h}\left[I_{E}^{n}+\frac{m_{1} h}{2}\left(\beta T^{n+1} V^{n+1} e^{\delta_{I_{E}} \Delta(n+1) h}+\beta T^{n+1-m_{1}} V^{n+1-m_{1}} e^{\delta_{I_{E}} \Delta\left(n+1-m_{1}\right) h}\right)\right]$,

with $\Delta=m_{1} h$.

Next, we make the following non-local approximations of the terms on the right side of the system (27)

$$
\left\{\begin{aligned}
\beta T(t) V(t) & \rightarrow \beta T^{n} V^{n} \\
-\beta T(t-\Delta) V(t-\Delta) e^{-\delta_{I_{E}} \Delta} & \rightarrow-\beta T^{n-m_{1}+1} V^{n-m_{1}} e^{-\delta_{I_{E}} \Delta} \\
-\delta_{I_{E}} I_{E}(t) & \rightarrow-\delta_{I_{E}} I_{E}^{n+1} \\
-\delta_{I} I(t) & \rightarrow-\delta_{I} I^{n+1} \\
N \delta_{I} I(t) & \rightarrow N \delta_{I} I^{n+1} \\
-(C+\beta T(t)) V(t) & \rightarrow-\left(C+\beta T^{n}\right) V^{n+1} \\
-\beta T(t) V(t) & \rightarrow-\beta T^{n+1} V^{n} \\
-\mu_{0} T(t) & \rightarrow-\mu_{0} T^{n+1}
\end{aligned}\right.
$$

Then, we approximate the derivatives on the left side of the system (27) as follows

$$
\left\{\begin{array}{l}
\frac{d_{N} I(t)}{d t} \rightarrow \frac{I^{n+1}-I^{n}}{\varphi(h)} \\
\frac{d_{N} V(t)}{d t} \rightarrow \frac{V^{n+1}-V^{n}}{\varphi(h)} \\
\frac{d_{N} T(t)}{d t} \rightarrow \frac{T^{n+1}-T^{n}}{\varphi(h)}
\end{array}\right.
$$


Consequently, the system (27) can be discretized as an implicit NSFD scheme given by

$$
\begin{aligned}
\frac{T^{n+1}-T^{n}}{\varphi(h)} & =\Lambda-\beta T^{n+1} V^{n}-\mu_{0} T^{n+1}, \\
\frac{I^{n+1}-I^{n}}{\varphi(h)} & =\beta T^{n-m_{1}+1} V^{n-m_{1}} e^{-\delta_{I_{E}}}{ }^{n}-\delta_{I} I^{n+1}, \\
\frac{V^{n+1}-V^{n}}{\varphi(h)} & =N \delta_{I} I^{n+1}-C V^{n+1}-\beta T^{n} V^{n+1} .
\end{aligned}
$$

And the explicit form is given by

$$
\begin{aligned}
T^{n+1} & =\frac{\varphi(h) \Lambda+T^{n}}{1+\varphi(h)\left(\beta V^{n}+\mu_{0}\right)}, \\
I^{n+1} & =\frac{\varphi(h) \beta T^{n-m_{1}+1} V^{n-m_{1}} e^{-\delta_{I_{E}}}+I^{n}}{1+\varphi(h) \delta_{I}}, \\
V^{n+1} & =\frac{\varphi(h) N \delta_{I} I^{n+1}+V^{n}}{1+\varphi(h)\left(C+\beta T^{n}\right)},
\end{aligned}
$$

where $m_{1}=\frac{\Delta}{h} \in \mathbb{N}$. The initial conditions of scheme (34) are given by

$$
T^{j}=\xi_{1}^{j}, V^{j}=\xi_{2}^{j}, j=-m_{1},-m_{1}+1, \cdots, 0 .
$$

The positivity of scheme (34) is trivially satisfied, since for $n>0$ it holds that $T^{n}, I^{n}, V^{n}$ are positive.

Theorem 6. Let $\left(T^{n}, I^{n}, V^{n}\right)$ be a solution of system (34). Then is uniformly bounded for all $n>0$.

Proof. From the first equation of scheme (33), one gets that

$$
\frac{T^{n+1}-T^{n}}{\varphi(h)}=\Lambda-\beta T^{n+1} V^{n}-\mu_{0} T^{n+1} \leq \Lambda-\mu_{0} T^{n+1} .
$$

When $n \rightarrow \infty$ and since $\varphi(h)=h+O\left(h^{2}\right)$, then $\varphi(h)$ coincide with 0 in the limit as $h \rightarrow 0$. This implies that $\limsup _{n \rightarrow \infty} T^{n} \leq \frac{\Lambda}{\mu_{0}}$.

Next, let $\mathcal{W}^{n}=T^{n-m_{1}}+e^{\delta_{I_{E}} \Delta} I^{n}$. From first and second equation of system (33), one obtains

$$
\begin{aligned}
\frac{\mathcal{W}^{n+1}-\mathcal{W}^{n}}{\varphi} & =\frac{T^{n-m_{1}+1}-T^{n-m_{1}}}{\varphi(h)}+e^{\delta_{I} \Delta} \frac{I^{n+1}-I^{n}}{\varphi(h)}=\Lambda-\mu_{0} T^{n-m_{1}+1}-\delta_{I} e^{\delta_{I E} \Delta} I^{n+1} \\
& \leq \Lambda-d \mathcal{W}^{n+1},
\end{aligned}
$$

where $d=\min \left\{\mu_{0}, \delta_{I}\right\}$. Thus, $\limsup _{n \rightarrow \infty} \mathcal{W}^{n} \leq \frac{\Lambda}{d}$. Therefore, $\limsup _{n \rightarrow \infty} I^{n} \leq \frac{\Lambda e^{-\delta_{I_{E}}} \Delta}{d}$. Then, give $\epsilon>0$ we can choose a $M \in \mathbb{N}$ such that $I^{n} \leq \frac{\Lambda e^{-\delta_{I_{E}} \Delta}}{d}+\epsilon$ for $n \geq M$. Using the last equation of (33) it is concluded that

$$
\frac{V^{n+1}-V^{n}}{\varphi(h)} \leq N \delta_{I} I^{n+1}-C V^{n+1} \leq N \delta_{I}\left(\frac{\Lambda e^{-\delta_{I_{E}}} \Delta}{d}+\epsilon\right)-C V^{n+1}
$$


for $n \geq M+1$. Then $\limsup _{n \rightarrow \infty} V^{n} \leq \frac{N \delta_{I}}{C}\left(\frac{\Lambda e^{-\delta_{I_{E}} \Delta}}{d}+\epsilon\right)$, and as is for all $\epsilon>0$ it follows that $\limsup _{n \rightarrow \infty} V^{n} \leq \frac{N \delta_{I}}{C}\left(\frac{\Lambda e^{-\delta_{I_{E}} \Delta}}{d}\right)$. This completes the proof. Moreover, from Equation (27) it follows that $I_{E}^{n}$ is bounded.

\subsection{Equilibrium Points of the NSFD Numerical Scheme}

The equilibrium points of the scheme (34) are given by analyzing the behavior of system when $n$ approaches to infinity. Thus, after a few calculations we find that

$$
\begin{aligned}
I^{*} & =\frac{\varphi(h) \beta T^{*} V^{*} e^{-\delta_{I_{E}} \Delta}+I^{*}}{1+\varphi(h) \delta_{I}} \\
V^{*} & =\frac{\varphi(h) N \delta_{I} I^{*}+V^{*}}{1+\varphi(h)\left(C+\beta T^{*}\right)} \\
T^{*} & =\frac{\varphi(h) \Lambda+T^{*}}{1+\varphi(h)\left(\beta V^{*}+\mu_{0}\right)} .
\end{aligned}
$$

Note that the equations of the scheme (35) correspond to Equations (14)-(16). Thus, the critical points of the discrete scheme will coincide in the limit $h \rightarrow 0$, with those of the continuous model.

\subsection{Local Stability of the NSFD Numerical Scheme}

For the study of the local stability of the critical points of the numerical scheme (34) it is necessary to use the following lemma:

Lemma 1. The roots of the quadratic polynomial $\lambda^{2}-a_{1} \lambda+a_{2}=0$, satisfy $\left|\lambda_{i}\right|<1$ for $i=1,2$ if and only if the following conditions hold:

$$
\begin{array}{ll}
\text { i. } & 1-a_{1}+a_{2}>0, \\
\text { ii. } & 1+a_{1}+a_{2}>0, \\
\text { iii. } & a_{2}<1 .
\end{array}
$$

Proof. See [7].

Theorem 7. The disease-free equilibrium point $P_{f}=\left(0,0, \frac{\Lambda}{\mu_{0}}\right)$ of the scheme (34) is locally asymptotically stable if $\mathcal{R}_{0}<1$.

Proof. Calculating the eigenvalues of the Jacobian matrix of the system (34) at the diseasefree point, we obtain the following characteristic polynomial

$$
\left(\frac{1}{1+\varphi(h) \mu_{0}}-\lambda\right)\left|\begin{array}{cc}
\frac{1}{1+\varphi(h) \delta_{I}}-\lambda & \frac{\varphi(h) \beta e^{-\delta_{I_{E}} \Delta} \Lambda}{\mu_{0}\left(1+\varphi(h) \delta_{I}\right)} \\
\frac{\mu_{0} h N \delta_{I}}{\mu_{0}+\mu_{0} h C+h \beta \Lambda} & \frac{\mu_{0}}{\mu_{0}+\mu_{0} h C+h \beta \Lambda}-\lambda
\end{array}\right|=0 .
$$

Thus, the first eigenvalue is

$$
\lambda_{1}=\frac{1}{1+\varphi(h) \mu_{0}}<1
$$

The other two eigenvalues, are the roots of quadratic polynomial

$$
\lambda^{2}-\left(\frac{1}{p}+\frac{\mu_{0}}{q}\right) \lambda+\frac{\mu_{0}-\varphi(h)^{2} \delta_{I} N \beta \Lambda e^{-\delta_{I_{E}} \Delta}}{\mu_{0} p q}=0,
$$


where $p=1+\varphi(h) \delta_{I}>0$ and $q=\mu_{0}+\mu_{0} \varphi(h) C+\varphi(h) \beta \Lambda$. Next, let $a_{1}=\frac{1}{p}+\frac{\mu_{0}}{q}$ and $a_{2}=\frac{\mu_{0}-\varphi(h)^{2} \delta_{I} N \beta \Lambda e^{-\delta_{I} \Delta}}{\mu_{0} p q}$. We have the following affirmations.

1. If $1>\mathcal{R}_{0}$, it follows that $\varphi(h)^{2} \delta_{I}\left(C \mu_{0}+\beta \Lambda\right)>\varphi(h)^{2} \delta_{I} N \beta \Lambda e^{-\delta_{I_{E}} \Delta}$. Thus,

$$
\begin{aligned}
\delta_{I}\left(\mu_{0}+\mu_{0} h C+h \beta \Lambda\right)>\mu_{0} \delta_{I}+\varphi(h) \delta_{I} N \beta \Lambda e^{-\delta_{I_{E}} \Delta} & \Longleftrightarrow \\
\left(1+\varphi(h) \delta_{I}\right) q>q+\varphi(h) \mu_{0} \delta_{I}+\varphi(h)^{2} \delta_{I} N \beta \Lambda e^{-\delta_{I_{E}} \Delta} & \Longleftrightarrow \\
p q+\mu_{0}>q+\varphi(h) \mu_{0} \delta_{I}+\varphi(h)^{2} \delta_{I} N \beta \Lambda e^{-\delta_{I_{E}} \Delta}+\mu_{0} & \Longleftrightarrow \\
p q+\mu_{0}>q+\varphi(h)^{2} \delta_{I} N \beta \Lambda e^{-\delta_{I_{E}} \Delta}+p \mu_{0} & \Longleftrightarrow \\
1-\left(\frac{1}{p}+\frac{\mu_{0}}{q}\right)+\frac{\mu_{0}-h^{2} \delta_{I} N \beta \Lambda e^{-\delta_{I_{E}} \Delta}}{p q} & >0
\end{aligned}
$$

Therefore, one gets that $1+a_{2}>a_{1}$.

2. Since $a_{1}>0$, it is sufficient to prove that $1+a_{2}>0$. By hypothesis $1>R_{0}$, then

$\mu_{0}+q+\varphi(h) \delta_{I} \mu_{0}+\varphi(h)^{2} \delta_{I}\left(\mu_{0} C+\beta \Lambda\right)>\varphi(h)^{2} \delta_{I}\left(\mu_{0} C+\beta \Lambda\right)>\varphi(h)^{2} \delta_{I} N \beta \Lambda e^{-\delta_{I_{E}} \Delta}$.

Accordingly

$$
\begin{aligned}
\mu_{0}+q+\varphi(h) \delta_{I}\left(\mu_{0}+\mu_{0} \varphi(h) C+\varphi(h) \beta \Lambda\right)>\varphi(h)^{2} \delta_{I} N \beta \Lambda e^{-\delta_{I_{E}} \Delta} & \Longleftrightarrow \\
\mu_{0}+q+\varphi(h) \delta_{I} q>\varphi(h)^{2} \delta_{I} N \beta \Lambda e^{-\delta_{I_{E}} \Delta} & \Longleftrightarrow \\
\mu_{0}+\left(1+\varphi(h) \delta_{I}\right) q>\varphi(h)^{2} \delta_{I} N \beta \Lambda e^{-\delta_{I_{E}} \Delta} & \Longleftrightarrow \\
1+\frac{\mu_{0}-\varphi(h)^{2} \delta_{I} N \beta \Lambda e^{-\delta_{I_{E}}}}{p q} & >0
\end{aligned}
$$

3. Given that

$$
\mu_{0}-\varphi(h)^{2} \delta_{I} N \beta \Lambda e^{-\delta_{I_{E}} \Delta}<\mu_{0}+\mu_{0} \varphi(h) C+\varphi(h) \beta \Lambda+\varphi(h) \delta_{I} q,
$$

then

$$
\frac{\mu_{0}-\varphi(h)^{2} \beta e^{-\delta_{I_{E}} \Delta} \Lambda N \delta_{I}}{p q}<1
$$

that is $a_{2}<1$.

Next, by virtue of Lemma 1 we have that the eigenvalues of the Jacobian matrix of the system (35) evaluated at $P_{f}$ satisfy $\left|\lambda_{i}\right|<1$. for $i=1,2$. Then $P_{f}$ is locally asymptotically stable if $\mathcal{R}_{0}<1$.

\subsection{Global Stability of the NSFD Numerical Scheme}

Several authors have used discrete Lyapunov functions to study the global behavior of numerical solutions generated by non-standard finite difference schemes (NSFD), see $[19,106-110]$. For the study of the global stability of the critical points of the numerical scheme (34) it is necessary to use the Lyapunov functions and Equation (28).

Theorem 8. The disease-free equilibrium point $P_{f}=\left(0,0, \frac{\Lambda}{\mu_{0}}\right)$ of the scheme (34) is globally asymptotically stable if $\mathcal{R}_{0} \leq 1$. 
Proof. Let the following Lyapunov function be

$$
\mathcal{L}^{n}=\frac{T^{0} g\left(\frac{T^{n}}{T^{0}}\right)+e^{\delta_{I_{E}} \Delta} I^{n}+\beta T^{0}\left(\frac{1}{C}+\varphi(h)\right) V^{n}}{\varphi(h)}+\sum_{i=n-m_{1}}^{n-1} \beta T^{i+1} V^{i} .
$$

Using the inequality $\ln z \leq z-1$, the difference of $\mathcal{L}^{n}$ in (37) satisfies

$$
\begin{aligned}
\mathcal{L}^{n+1}-\mathcal{L}^{n} & \leq\left(\frac{T^{n+1}-T^{0}}{T^{n+1}}\right)\left(\Lambda-\beta T^{n+1} V^{n}-\mu_{0} T^{n+1}\right) \\
& +e^{\delta_{I_{E}}}\left(\beta T^{n-m_{1}+1} V^{n-m_{1}} e^{-\delta_{I_{E}} \Delta}-\delta_{I} I^{n+1}\right) \\
& +\frac{\beta T^{0}}{C}\left(N \delta_{I} I^{n+1}-C V^{n+1}-\beta T^{n} V^{n+1}\right)+\beta T^{0}\left(V^{n+1}-V^{n}\right) \\
& +\beta T^{n+1} V^{n}-\beta T^{n-m_{1}+1} V^{n-m_{1}} \\
& \leq-\mu_{0} \frac{T^{n+1}-T^{0}}{T^{n+1}}-e^{\delta_{I} \Delta} \delta_{I} I^{n+1}\left(1-\mathcal{R}_{0}\right) .
\end{aligned}
$$

It follows that $\mathcal{L}^{n+1}-\mathcal{L}^{n} \leq 0$ for all $n \leq 0$ if $\mathcal{R}_{0} \leq 1$. This means that $\mathcal{L}^{n}$ is monotone decreasing sequence and since $\mathcal{L}^{n} \geq 0$ for $n \geq 0$ then there exists a limit, i.e., $\lim _{n \rightarrow \infty} \mathcal{L}^{n} \geq 0$. Hence $\lim _{n \rightarrow \infty}\left(\mathcal{L}^{n+1}-\mathcal{L}^{n}\right)=0$, which implies that $\lim _{n \rightarrow \infty} T^{n}=T^{0}, \lim _{n \rightarrow \infty} I^{n}=0$, and from (34) $\lim _{n \rightarrow \infty} V^{n}=0$. By the previous analysis, we conclude that $P_{f}$ is globally asymptotically stable for scheme (34).

\section{Numerical Simulations Using the NSFD Scheme}

In this section, we present some numerical solutions of the mathematical model of HIV. To carry out the simulations we use the constructed NSFD numerical scheme (34). We choose the parameter values based on existing experimental data and previous model studies, see [54,106,111,112]. The values of these parameters are given in Tables 1 and 2. For the first case we choose values such $\mathcal{R}_{0}<1$ and for the second we have the case $\mathcal{R}_{0}>1$.

Table 1. Parameter values for the numerical simulations when $\mathcal{R}_{0}<1$.

\begin{tabular}{cl}
\hline Parameters & Value \\
\hline$\beta$ & $4.8 \times 10^{-6} \mathrm{~mm}^{3}$ day $^{-1}$ \\
$C$ & $3 \mathrm{~mm}^{3}$ day $^{-1}$ \\
$\Lambda$ & 2.3 day $^{-1}$ \\
$\delta_{I}$ & 0.24 day $^{-1}$ \\
$\delta_{I_{E}}$ & 0.05 day $^{-1}$ \\
$\mu_{0}$ & 0.0046 day $^{-1}$ \\
$\Delta$ & 0.4 day \\
$N$ & 500 \\
$V_{0}$ & $1 \mathrm{~mm}^{-3}$ \\
$T_{0}$ & $100 \mathrm{~mm}^{-3}$ \\
$I_{E_{0}}$ & 0 \\
$I_{0}$ & 0 \\
\hline
\end{tabular}


Table 2. Parameter values for the numerical simulations when $\mathcal{R}_{0}>1$.

\begin{tabular}{cl}
\hline Parameters & Value \\
\hline$\beta$ & $4.8 \times 10^{-6} \mathrm{~mm}^{3} \mathrm{day}^{-1}$ \\
$C$ & $2.4 \mathrm{~mm}^{3} \mathrm{day}^{-1}$ \\
$\Lambda$ & $23 \mathrm{day}^{-1}$ \\
$\delta_{I}$ & $0.2 \mathrm{day}^{-1}$ \\
$\delta_{I_{E}}$ & $0.05 \mathrm{day}^{-1}$ \\
$\mu_{0}$ & $0.0046 \mathrm{day}^{-1}$ \\
$\Delta$ & $0.4 \mathrm{day}$ \\
$N$ & 500 \\
$V_{0}$ & $1 \mathrm{~mm}^{-3}$ \\
$T_{0}$ & $100 \mathrm{~mm}^{-3}$ \\
$I_{E_{0}}$ & 1 \\
$I_{0}$ & 1 \\
\hline
\end{tabular}

For the numerical simulations we use a small step size, $h=0.001$. For the discrete derivatives given in system (33), we have many options for the denominator function $\varphi$. We have chosen $\varphi(h)=(1-\exp (-h p)) / p$, where $p=\max \left\{A, \Delta, \mu_{0}, \delta_{I}, \delta_{I_{E}}\right\}$ are parameters of the model and included in the numerical scheme (33). This particular $\varphi$ usually provides better numerical results based on previous articles related to NSFD schemes $[113,114]$. In addition, this option satisfies the asymptotic relation $\varphi(h)=h+$ $O\left(h^{2}\right)$, and Rule 1 . We performed numerical simulations to show that the solutions obtained by the proposed NSFD scheme and the well-known MATLAB routine dde23 agree. A great advantage of the proposed NSFD numerical scheme (34) is that the computation time is smaller. For the first case, the numerical solution using the NSFD scheme is obtained in approximately $0.083992 \mathrm{~s}$, while the dde 23 routine spent $2.573003 \mathrm{~s}$. For the second case, the numerical solution using the NSFD scheme is obtained in approximately $0.176461 \mathrm{~s}$, while the routine dde2 3 spent $11.181812 \mathrm{~s}$. The results obtained are shown in Figures 2 and 3 respectively. It can be seen that the numerical solution of the proposed NSFD numerical scheme (34) and the one obtained by means of the routine dde23 agree.
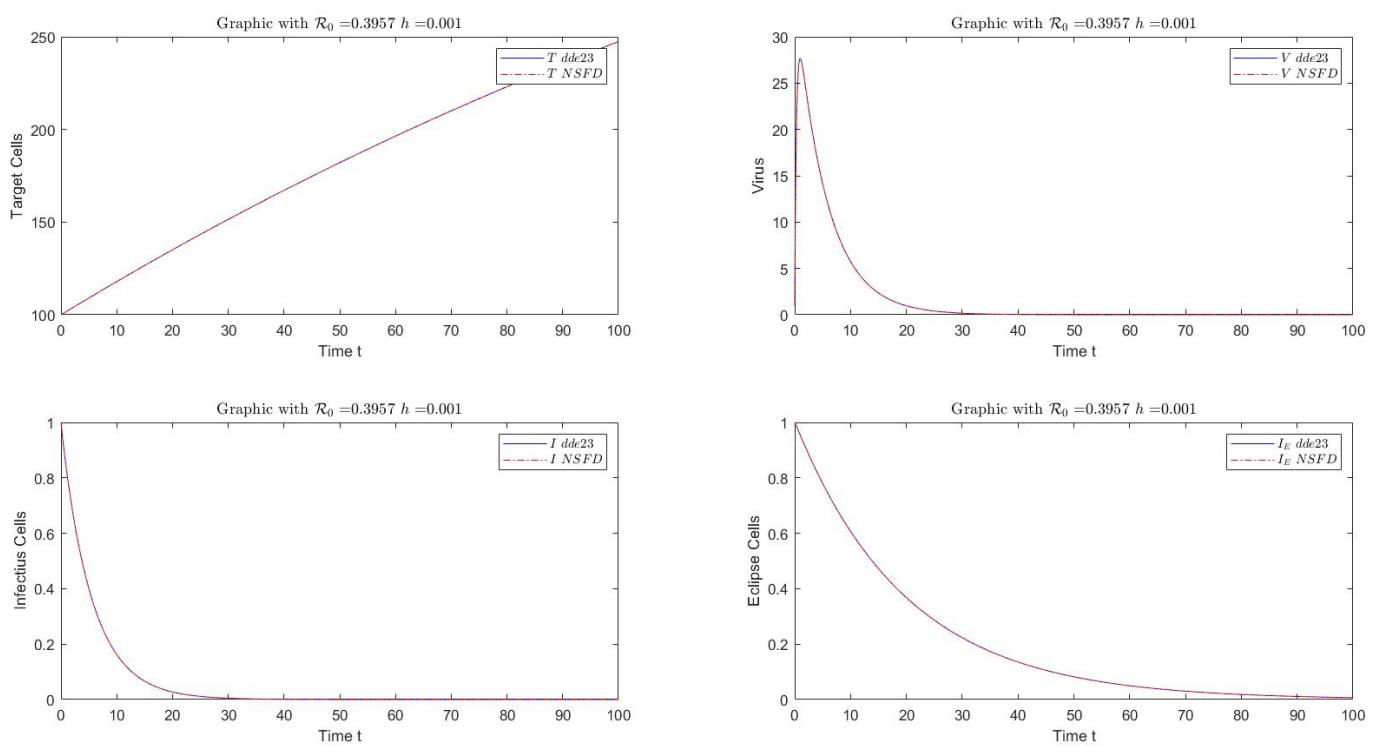

Figure 2. Simulation NSFD versus dde23 when $\mathcal{R}_{0}<1$. 

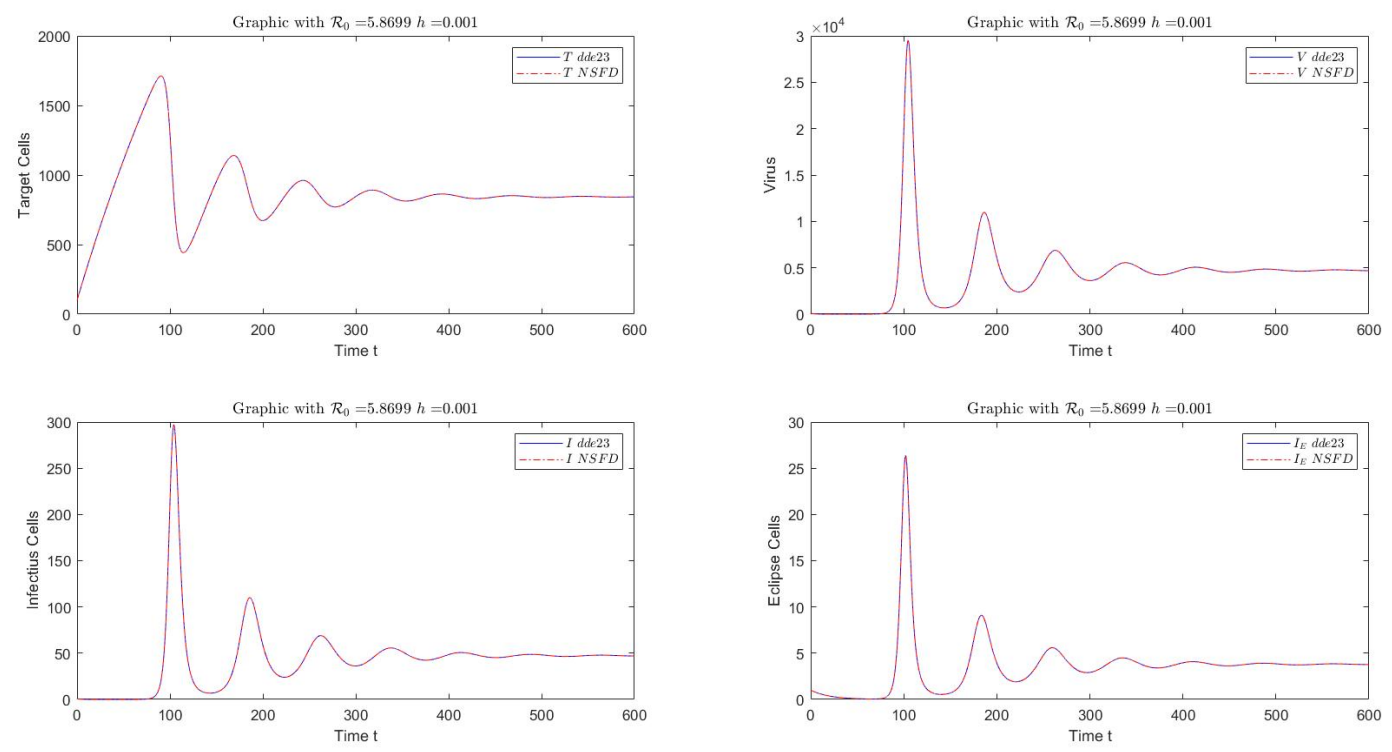

Figure 3. Simulation NSFD versus dde23 when $\mathcal{R}_{0}>1$.

\section{Conclusions}

We proposed a mathematical model based on a set of delay differential equations that describe intracellular HIV infection. The model considers three different subpopulations of cells and the HIV virus. The mathematical model is formulated in such a way that takes into account the time between viral entry into a target cell and the production of new virions. Moreover, this time is included using a discrete time delay. We analyzed the local stability of the infection-free and endemic equilibrium states. By using a suitable Lyapunov functional and the LaSalle invariant principle, it is proved that if the basic reproduction ratio is less than unity, the infection-free equilibrium is globally asymptotically stable. In addition, we designed a non-standard difference scheme that preserves some properties of the continuous model. We prove that the constructed NSFD scheme has the same equilibrium points of the continuous model, and the disease-free equilibrium holds the same stability properties. As required by the constraints of the real phenomena, the solutions given by the numerical scheme satisfy positivity and boundedness. The numerical simulations corroborate that the developed NSFD numerical scheme preserves the properties of the continuous model and presents a robust behavior when working with a variety of parameter values.

Author Contributions: Conceptualization, G.G.-P.; Formal analysis, G.G.-P., A.J.A. and J.J.N.; Investigation, G.G.-P. and A.J.A.; Methodology, G.G.-P., A.J.A., M.C. and N.D.L.E.; Software, G.G.-P.; Supervision, G.G.-P. and A.J.A.; Validation, A.J.A.; Visualization, A.J.A., J.J.N., M.C. and N.D.L.E.; Writing-original draft, G.G.-P.; Writing-review and editing, G.G.-P., M.C. and N.D.L.E. All authors have read and agreed to the published version of the manuscript.

Funding: This research received no external funding.

Acknowledgments: The authors are grateful to the reviewers for their careful reading of this manuscript and their useful comments to improve the content of this paper.

Conflicts of Interest: The authors declare no conflict of interest.

\section{References}

1. Nelson, K.E.; Williams, C.M. Early History of Infectious Disease: Epidemiology and Control of Infectious Diseases; Jones \& Bartlett Publishers: Burlington, MA, USA, 2007; Volume 2, pp. 3-23.

2. Dabis, F.; Bekker, L.G. We still need to beat HIV. Science 2017, 357, 335. [CrossRef] 
3. Ayele, T.A.; Worku, A.; Kebede, Y.; Alemu, K.; Kasim, A.; Shkedy, Z. Choice of initial antiretroviral drugs and treatment outcomes among HIV-infected patients in sub-Saharan Africa: Systematic review and meta-analysis of observational studies. System. Rev. 2017, 6, 173. [CrossRef]

4. Duvergé, A.; Negroni, M. Pseudotyping Lentiviral Vectors: When the Clothes Make the Virus. Viruses 2020, 12, 1311. [CrossRef]

5. Dubrow, R.; Silverberg, M.J.; Park, L.S.; Crothers, K.; Justice, A.C. HIV infection, aging, and immune function: Implications for cancer risk and prevention. Curr. Opin. Oncol. 2012, 24, 506. [CrossRef]

6. Verma, M.; Erwin, S.; Abedi, V.; Hontecillas, R.; Hoops, S.; Leber, A.; Bassaganya-Riera, J.; Ciupe, S.M. Modeling the mechanisms by which HIV-associated immunosuppression influences HPV persistence at the oral mucosa. PLoS ONE 2017, 12, e0168133. [CrossRef]

7. Brauer, F.; Castillo-Chavez, C. Mathematical Models in Population Biology and Epidemiology; Springer: Berlin, Germany, 2001; Volume 40.

8. González-Parra, G.; Dobrovolny, H.M. Assessing uncertainty in A2 respiratory syncytial virus viral dynamics. Comput. Math. Methods Med. 2015, 2015. [CrossRef]

9. Beauchemin, C.A.; Handel, A. A review of mathematical models of influenza A infections within a host or cell culture: Lessons learned and challenges ahead. BMC Public Health 2011, 11, S7. [CrossRef] [PubMed]

10. Alade, T.O. On the generalized Chikungunya virus dynamics model with distributed time delays. Int. J. Dyn. Control 2020, 2020, 1-11. [CrossRef]

11. Dobrovolny, H.M.; Reddy, M.B.; Kamal, M.A.; Rayner, C.R.; Beauchemin, C.A. Assessing mathematical models of influenza infections using features of the immune response. PLoS ONE 2013, 8, e57088. [CrossRef]

12. Doekes, H.M.; Fraser, C.; Lythgoe, K.A. Effect of the Latent Reservoir on the Evolution of HIV at the Within-and Between-Host Levels. PLoS Comput. Biol. 2017, 13, e1005228. [CrossRef] [PubMed]

13. González-Parra, G.; Dobrovolny, H.M.; Aranda, D.F.; Chen-Charpentier, B.; Rojas, R.A.G. Quantifying rotavirus kinetics in the REH tumor cell line using in vitro data. Virus Res. 2018, 244, 53-63. [CrossRef] [PubMed]

14. González-Parra, G.; Dobrovolny, H.M. The rate of viral transfer between upper and lower respiratory tracts determines RSV illness duration. J. Math. Biol. 2019, 79, 467-483. [CrossRef] [PubMed]

15. Maheswari, M.; Krishnapriya, P.; Krishnan, K.; Pitchaimani, M. A mathematical model of HIV-1 infection within host cell to cell viral transmissions with RTI and discrete delays. J. Appl. Math. Comput. 2018, 56, 151-178. [CrossRef]

16. Pinky, L.; Gonzalez-Parra, G.; Dobrovolny, H.M. Effect of stochasticity on coinfection dynamics of respiratory viruses. BMC Bioinf. 2019, 20, 1-12. [CrossRef]

17. Song, H.; Jiang, W.; Liu, S. Virus dynamics model with intracellular delays and immune response. Math. Biosci. Eng. 2015, 12, 185. [CrossRef]

18. Wang, Y.; Liu, X. Stability and Hopf bifurcation of a within-host chikungunya virus infection model with two delays. Math. Comput. Simul. 2017, 138, 31-48. [CrossRef]

19. Zhou, J.; Yang, Y. Global dynamics of a discrete viral infection model with time delay, virus-to-cell and cell-to-cell transmissions. J. Diff. Equ. Appl. 2017, 23, 1853-1868. [CrossRef]

20. Nelson, P.W.; Perelson, A.S. Mathematical analysis of delay differential equation models of HIV-1 infection. Math. Biosci. 2002, 179, 73-94. [CrossRef]

21. Pawelek, K.A.; Liu, S.; Pahlevani, F.; Rong, L. A model of HIV-1 infection with two time delays: Mathematical analysis and comparison with patient data. Math. Biosci. 2012, 235, 98-109. [CrossRef]

22. Cooper, A.; García, M.; Petrovas, C.; Yamamoto, T.; Koup, R.A.; Nabel, G.J. HIV-1 causes CD4 cell death through DNA-dependent protein kinase during viral integration. Nature 2013, 498, 376. [CrossRef]

23. Doitsh, G.; Galloway, N.L.; Geng, X.; Yang, Z.; Monroe, K.M.; Zepeda, O.; Hunt, P.W.; Hatano, H.; Sowinski, S.; Muñoz-Arias, I.; et al. Cell death by pyroptosis drives CD4 T-cell depletion in HIV-1 infection. Nature 2014, 505, 509. [CrossRef] [PubMed]

24. Mickens, R.E. Nonstandard Finite Difference Models of Differential Equations; World Scientific: Singapore, 1994.

25. Mickens, R.E. Applications of Nonstandard Finite Difference Schemes; World Scientific: Singapore, 2000.

26. Mickens, R.E. Nonstandard finite difference schemes for differential equations. J. Diff. Equ. Appl. 2002, 8, 823-847. [CrossRef]

27. Mickens, R.E. Dynamic consistency: A fundamental principle for constructing nonstandard finite difference schemes for differential equations. J. Diff. Equ. Appl. 2005, 11, 645-653. [CrossRef]

28. Martin-Vaquero, J.; Queiruga-Dios, A.; del Rey, A.M.; Encinas, A.H.; Guillen, J.H.; Sanchez, G.R. Variable step length algorithms with high-order extrapolated non-standard finite difference schemes for a SEIR model. J. Comput. Appl. Math. 2018, 330, 848-854. [CrossRef]

29. Farooqi, A.; Ahmad, R.; Farooqi, R.; Alharbi, S.O.; Baleanu, D.; Rafiq, M.; Khan, I.; Ahmad, M. An Accurate Predictor-CorrectorType Nonstandard Finite Difference Scheme for an SEIR Epidemic Model. J. Math. 2020, 2020. [CrossRef]

30. Khalsaraei, M.M.; Shokri, A.; Ramos, H.; Heydari, S. A positive and elementary stable nonstandard explicit scheme for a mathematical model of the influenza disease. Math. Comput. Simul. 2021, 182, 397-410. [CrossRef]

31. Dang, Q.A.; Hoang, M.T. Positive and elementary stable explicit nonstandard Runge-Kutta methods for a class of autonomous dynamical systems. Int. J. Comput. Math. 2020, 97, 2036-2054. [CrossRef]

32. Sweilam, N.; Al-Mekhlafi, S.; Shatta, S.; Baleanu, D. Numerical Study for Two Types Variable-Order Burgers' Equations with Proportional Delay. Appl. Numer. Math. 2020, 156, 364-376. [CrossRef] 
33. Hoang, M.T.; Egbelowo, O.F. Dynamics of a fractional-order hepatitis b epidemic model and its solutions by nonstandard numerical schemes. In Mathematical Modelling and Analysis of Infectious Diseases; Springer: Berlin, Germany, 2020 ; pp. 127-153.

34. Egbelowo, O.F.; Hoang, M.T. Global dynamics of target-mediated drug disposition models and their solutions by nonstandard finite difference method. J. Appl. Math. Comput. 2020, 1-23. [CrossRef]

35. Alexander, M.E.; Summers, A.R.; Moghadas, S.M. Neimark-Sacker bifurcations in a non-standard numerical scheme for a class of positivity-preserving ODEs. Proc. R. Soc. A Math. Phys. Eng. Sci. 2006, 462, 3167-3184. [CrossRef]

36. Dumont, Y.; Lubuma, J.M.S. Non-standard finite-difference methods for vibro-impact problems. Proc. R. Soc. A Math. Phys. Eng. Sci. 2005, 461, 1927-1950. [CrossRef]

37. Bruggeman, J.; Burchard, H.; Kooi, B.W.; Sommeijer, B. A second-order, unconditionally positive, mass-conserving integration scheme for biochemical systems. Appl. Numer. Math. 2007, 57, 36-58. [CrossRef]

38. Arenas, A.J.; Moraño, J.A.; Cortés, J.C. Non-standard numerical method for a mathematical model of RSV epidemiological transmission. Comput. Math. Appl. 2008, 56, 670-678. [CrossRef]

39. Dimitrov, D.T.; Kojouharov, H.V. Stability-preserving finite-difference methods for general multi-dimensional autonomous dynamical systems. Int. J. Numer. Anal. Model 2007, 4, 282-292.

40. Dimitrov, D.T.; Kojouharov, H.V. Nonstandard finite-difference methods for predator-prey models with general functional response. Math. Comput. Simul. 2008, 78,1-11. [CrossRef]

41. Dimitrov, D.T.; Kojouharov, H.V. Nonstandard finite-difference schemes for general two-dimensional autonomous dynamical systems. Appl. Math. Lett. 2005, 18, 769-774. [CrossRef]

42. Gumel, A.B. A competitive numerical method for a chemotherapy model of two HIV subtypes. Appl. Math. Comput. 2002, 131, 329-337. [CrossRef]

43. Jansen, H.; Twizell, E.H. An unconditionally convergent discretization of the SEIR model. Math. Comput. Simul. 2002, 58, 147-158. [CrossRef]

44. Obaid, H.A.; Ouifki, R.; Patidar, K.C. An unconditionally stable nonstandard finite difference method applied to a mathematical model of HIV infection. Int. J. Appl. Math. Comput. Sci. 2013, 23, 357-372. [CrossRef]

45. González-Parra, G.; Arenas, A.J.; Chen-Charpentier, B.M. Combination of nonstandard schemes and Richardson's extrapolation to improve the numerical solution of population models. Math. Comput. Model. 2010, 52, 1030-1036. [CrossRef]

46. Ahmad, A.; Farman, M.; Akgül, A.; Bukhari, N.; Imtiaz, S. Mathematical analysis and numerical simulation of co-infection of TB-HIV. Arab J. Basic Appl. Sci. 2020, 27, 431-441. [CrossRef]

47. Asai, Y.; Herrmann, E.; Kloeden, P.E. Stable integration of stiff random ordinary differential equations. Stochast. Anal. Appl. 2013, 31, 293-313. [CrossRef]

48. Baker, C.T.; Bocharov, G.; Ford, J.M.; Lumb, P.M.; Norton, S.J.; Paul, C.; Junt, T.; Krebs, P.; Ludewig, B. Computational approaches to parameter estimation and model selection in immunology. J. Comput. Appl. Math. 2005, 184, 50-76. [CrossRef]

49. Reinharz, V.; Churkin, A.; Dahari, H.; Barash, D. A robust and efficient numerical method for RNA-mediated viral dynamics. Front. Appl. Math. Statist. 2017, 3, 20. [CrossRef] [PubMed]

50. Bocharov, G.; Marchuk, G.; Romanyukha, A. Numerical solution by LMMs of stiff delay differential systems modelling an immune response. Numer. Math. 1996, 73, 131-148. [CrossRef]

51. Rihan, F.A.; Rahman, D.A.; Lakshmanan, S.; Alkhajeh, A. A time delay model of tumour-immune system interactions: Global dynamics, parameter estimation, sensitivity analysis. Appl. Math. Comput. 2014, 232, 606-623. [CrossRef]

52. Beauchemin, C.A.; McSharry, J.J.; Drusano, G.L.; Nguyen, J.T.; Went, G.T.; Ribeiro, R.M.; Perelson, A.S. Modeling amantadine treatment of influenza A virus in vitro. J. Theor. Biol. 2008, 254, 439-451. [CrossRef]

53. Hill, A.L.; Rosenbloom, D.I.; Nowak, M.A.; Siliciano, R.F. Insight into treatment of HIV infection from viral dynamics models. Immunol. Rev. 2018, 285, 9-25. [CrossRef]

54. Noecker, C.; Schaefer, K.; Zaccheo, K.; Yang, Y.; Day, J.; Ganusov, V. Simple mathematical models do not accurately predict early SIV dynamics. Viruses 2015, 7, 1189-1217. [CrossRef]

55. Perelson, A.S. Modelling viral and immune system dynamics. Nat. Rev. Immunol. 2002, 2, 28. [CrossRef]

56. Banerjee, S.; Guedj, J.; Ribeiro, R.M.; Moses, M.; Perelson, A.S. Estimating biologically relevant parameters under uncertainty for experimental within-host murine West Nile virus infection. J. R. Soc. Interface 2016, 13, 20160130. [CrossRef] [PubMed]

57. Miao, H.; Xia, X.; Perelson, A.S.; Wu, H. On identifiability of nonlinear ODE models and applications in viral dynamics. SIAM Rev. 2011, 53, 3-39. [CrossRef] [PubMed]

58. Kirschner, D.; Pienaar, E.; Marino, S.; Linderman, J.J. A review of computational and mathematical modeling contributions to our understanding of Mycobacterium tuberculosis within-host infection and treatment. Curr. Opin. Syst. Biol. 2017, 3, 170-185. [CrossRef]

59. Hethcote, H.W. The mathematics of infectious diseases. SIAM Rev. 2000, 42, 599-653. [CrossRef]

60. Hethcote, H.W.; Van den Driessche, P. An SIS epidemic model with variable population size and a delay. J. Math. Biol. 1995, 34, 177-194. [CrossRef]

61. Baltes, A.; Akpinar, F.; Inankur, B.; Yin, J. Inhibition of infection spread by co-transmitted defective interfering particles. PLoS ONE 2017, 12, e0184029. [CrossRef]

62. Liao, L.E.; Iwami, S.; Beauchemin, C.A. (In) validating experimentally derived knowledge about influenza A defective interfering particles. J. R. Soc. Interface 2016, 13, 20160412. [CrossRef] 
63. Ho, D.D.; Neumann, A.U.; Perelson, A.S.; Chen, W.; Leonard, J.M.; Markowitz, M. Rapid turnover of plasma virions and CD4 lymphocytes in HIV-1 infection. Nature 1995, 373, 123. [CrossRef]

64. Goto, T.; Harada, S.; Yamamoto, N.; Nakai, M. Entry of human immunodeficiency virus (HIV) into MT-2, human T cell leukemia virus carrier cell line. Arch. Virol. 1988, 102, 29-38. [CrossRef]

65. Platt, E.J.; Kozak, S.L.; Durnin, J.P.; Hope, T.J.; Kabat, D. Rapid dissociation of HIV-1 from cultured cells severely limits infectivity assays, causes the inactivation ascribed to entry inhibitors, and masks the inherently high level of infectivity of virions. J. Virol. 2010, 84, 3106-3110. [CrossRef]

66. Bai, F.; Huff, K.E.; Allen, L.J. The effect of delay in viral production in within-host models during early infection. J. Biol. Dyn. 2019, 13, 47-73. [CrossRef] [PubMed]

67. Cao, P.; McCaw, J.M. The mechanisms for within-host influenza virus control affect model-based assessment and prediction of antiviral treatment. Viruses 2017, 9, 197. [CrossRef] [PubMed]

68. Holder, B.P.; Beauchemin, C.A. Exploring the effect of biological delays in kinetic models of influenza within a host or cell culture. BMC Public Health 2011, 11, S10. [CrossRef] [PubMed]

69. Dixit, N.M.; Markowitz, M.; Ho, D.D.; Perelson, A.S. Estimates of intracellular delay and average drug efficacy from viral load data of HIV-infected individuals under antiretroviral therapy. Antivir. Ther. 2004, 9, 237-246.

70. Kakizoe, Y.; Nakaoka, S.; Beauchemin, C.A.; Morita, S.; Mori, H.; Igarashi, T.; Aihara, K.; Miura, T.; Iwami, S. A method to determine the duration of the eclipse phase for in vitro infection with a highly pathogenic SHIV strain. Scient. Rep. 2015, 5, 10371. [CrossRef] [PubMed]

71. Keyfitz, B.L.; Keyfitz, N. The McKendrick partial differential equation and its uses in epidemiology and population study. Math. Comput. Model. 1997, 26, 1-9. [CrossRef]

72. Kuang, Y. Delay Differential Equations: With Applications in Population Dynamics, 1st ed.; Mathematics in Science and Engineering 191; Elsevier: Amsterdam, The Netherlands; Academic Press: Cambridge, MA, USA, 1993.

73. Driver, R.D. Ordinary and Delay Differential Equations, 1st ed.; Applied Mathematical Sciences 20; Springer: New York, NY, USA, 1977.

74. Anderson, R. Transmission dynamics and control of infectious disease agents. In Population Biology of Infectious Diseases; Springer: Berlin, Germany, 1982; pp. 149-176.

75. Diekmann, O.; Heesterbeek, J.; Roberts, M. The construction of next-generation matrices for compartmental epidemic models. J. R. Soc. Interface 2009, 2009, rsif20090386. [CrossRef]

76. González-Parra, G.; Arenas, A.; Diego, F.; Aranda, L.S. Modeling the epidemic waves of AH1N1/09 influenza around the world. Spat. Spatio-Temp. Epidemiol. 2011, 2, 219-226. [CrossRef]

77. Gonzalez-Parra, G.; Díaz-Rodríguez, M.; Arenas, A.J. Mathematical modeling to design public health policies for Chikungunya epidemic using optimal control. Opt. Control Appl. Methods 2020, 41, 1584-1603. [CrossRef]

78. Jang, S.R.J. On a discrete West Nile epidemic model. Comput. Appl. Math. 2007, 26, 397-414. [CrossRef]

79. Sekiguchi, M. Permanence of some discrete epidemic models. Int. J. Biomath. 2009, 2, 443-461. [CrossRef]

80. Chinviriyasit, S.; Chinviriyasit, W. Numerical modelling of an SIR epidemic model with diffusion. Appl. Math. Comput. 2010, 216, 395-409. [CrossRef]

81. Enatsu, Y.; Nakata, Y.; Muroya, Y. Global stability for a class of discrete SIR epidemic models. Math. Biosci. Eng. 2010, 7, 347-361.

82. Muroya, Y.; Nakata, Y.; Izzo, G.; Vecchio, A. Permanence and global stability of a class of discrete epidemic models. Nonlinear Anal. Real World Appl. 2011, 12, 2105-2117. [CrossRef]

83. Jódar, L.; Villanueva, R.J.; Arenas, A.J.; González, G.C. Nonstandard numerical methods for a mathematical model for influenza disease. Math. Comput. Simul. 2008, 79, 622-633. [CrossRef]

84. Lambert, J. Computational Methods in Ordinary Differential Equations; John Wiley \& Sons: Hoboken, NJ, USA, 1973.

85. Shishkin, G.I. The Richardson scheme for the singularly perturbed parabolic reaction-diffusion equation in the case of a discontinuous initial condition. Computat. Math. Math. Phys. 2009, 49, 1348-1368. [CrossRef]

86. Al'shin, A.; Al'shina, E. Numerical diagnosis of blow-up of solutions of pseudoparabolic equations. J. Math. Sci. 2008, 148, 143-162. [CrossRef]

87. Munyakazi, J.B.; Patidar, K.C. On Richardson extrapolation for fitted operator finite difference methods. Appl. Math. Comput. 2008, 201, 465-480. [CrossRef]

88. Burg, C.; Erwin, T. Application of Richardson extrapolation to the numerical solution of partial differential equations. Numer. Methods Part. Diff. Equ. 2009, 25, 810-832. [CrossRef]

89. Gurski, K. A simple construction of nonstandard finite-difference schemes for small nonlinear systems applied to SIR models. Comput. Math. Appl. 2013, 66, 2165-2177. [CrossRef]

90. Munyakazi, J.B.; Patidar, K.C.; Sayi, M.T. A robust fitted operator finite difference method for singularly perturbed problems whose solution has an interior layer. Math. Comput. Simul. 2019, 160, 155-167. [CrossRef]

91. Clermont, G.; Zenker, S. The inverse problem in mathematical biology. Math. Biosc. 2015, 260, 11-15. [CrossRef] [PubMed]

92. Pollicott, M.; Wang, H.; Weiss, H. Extracting the time-dependent transmission rate from infection data via solution of an inverse ODE problem. J. Biol. Dyn. 2012, 6, 509-523. [CrossRef] [PubMed]

93. González-Parra, G.; Benincasa, T. Mathematical modeling and numerical simulations of Zika in Colombia considering mutation. Math. Comput. Simul. 2019, 163, 1-18. 
94. Arthur, J.G.; Tran, H.T.; Aston, P. Feasibility of parameter estimation in hepatitis C viral dynamics models. J. Inver. Ill-Posed Probl. 2017, 25, 69-80. [CrossRef]

95. Hale, J.K.; Lunel, S.M.V. Introduction to Functional Differential Equations; Springer Science \& Business Media: Berlin, Germany, 2013; Volume 99.

96. Smith, H.L. An Introduction to Delay Differential Equations with Applications to the Life Sciences; Springer: New York, NY, USA, 2011; Volume 57.

97. Mukandavire, Z.; Chiyaka, C.; Garira, W.; Musuka, G. Mathematical analysis of a sex-structured HIV/AIDS model with a discrete time delay. Nonlinear Anal. Theory Methods Appl. 2009, 71, 1082-1093. [CrossRef]

98. Asai, Y.; Kloeden, P.E. Numerical schemes for ordinary delay differential equations with random noise. Appl. Math. Comput. 2019, 347, 306-318. [CrossRef]

99. Engelborghs, K.; Luzyanina, T.; Roose, D. Numerical bifurcation analysis of delay differential equations using DDE-BIFTOOL. ACM Trans. Math. Softw. (TOMS) 2002, 28, 1-21. [CrossRef]

100. Jamilla, C.; Mendoza, R.; Mező, I. Solutions of neutral delay differential equations using a generalized Lambert W function. Appl. Math. Comput. 2020, 382, 125334. [CrossRef]

101. Singh, H. Numerical simulation for fractional delay differential equations. Int. J. Dyn. Control 2020, 1-12. [CrossRef]

102. Baker, C.T.; Paul, C.A.; Willé, D.R. Issues in the numerical solution of evolutionary delay differential equations. Adv. Comput. Math. 1995, 3, 171-196. [CrossRef]

103. García, M.; Castro, M.; Martín, J.; Rodríguez, F. Exact and nonstandard numerical schemes for linear delay differential models. Appl. Math. Comput. 2018, 338, 337-345. [CrossRef]

104. Manna, K. A non-standard finite difference scheme for a diffusive HBV infection model with capsids and time delay. J. Diff. Equ. Appl. 2017, 23, 1901-1911. [CrossRef]

105. Patidar, K.C.; Sharma, K.K. $\varepsilon$-uniformly convergent non-standard finite difference methods for singularly perturbed differential difference equations with small delay. Appl. Math. Comput. 2006, 175, 864-890. [CrossRef]

106. Xu, J.; Geng, Y. Dynamic Consistent NSFD Scheme for a Delayed Viral Infection Model with Immune Response and Nonlinear Incidence. Discrete Dyn. Nat. Soc. 2017, 2017, 1-13. [CrossRef]

107. $\mathrm{Xu}, \mathrm{J} . ; \mathrm{Geng}, \mathrm{Y}$. Stability preserving NSFD scheme for a delayed viral infection model with cell-to-cell transmission and general nonlinear incidence. J. Diff. Equ. Appl. 2017, 23, 893-916. [CrossRef]

108. Ding, D.; Ma, Q.; Ding, X. An unconditionally positive and global stability preserving NSFD scheme for an epidemic model with vaccination. Int. J. Appl. Math. Comput. Sci. 2014, 24, 635-646. [CrossRef]

109. Liu, J.; Peng, B.; Zhang, T. Effect of discretization on dynamical behavior of SEIR and SIR models with nonlinear incidence. Appl. Math. Lett. 2015, 39, 60-66. [CrossRef]

110. Hattaf, K.; Lashari, A.A.; Boukari, B.E.; Yousfi, N. Effect of Discretization on Dynamical Behavior in an Epidemiological Model. Diff. Equ. Dyn. Syst. 2015, 23, 403-413. [CrossRef]

111. Culshaw, R.; Ruan, S. A delay-differential equation model of HIV infection of CD4 T-cells. Math. Biosci. 2000, 165, 27-39. [CrossRef]

112. Toro-Zapata, H.; Caicedo-Casso, A.; Lee, S. The Role of Immune Response in Optimal HIV Treatment Interventions. Processes 2018, 6, 102. [CrossRef]

113. Mickens, R.E. Calculation of denominator functions for nonstandard finite difference schemes for differential equations satisfying a positivity condition. Numer. Methods Part. Diff. Equ. An Int. J. 2007, 23, 672-691. [CrossRef]

114. Mickens, R.E.; Smith, A. Finite-difference models of ordinary differential equations: Influence of denominator functions. J. Franklin Inst. 1990, 327, 143-149. [CrossRef] 